\title{
Measuring and Analysing the Effect of Openings and Vibration on Reusable Pharmaceutical Insulated Boxes with Daily Distribution
}

\author{
Péter Böröcz \\ Széchenyi István University \\ boroczp@sze.hu \\ Ákos Mojzes \\ Széchenyi István University \\ mojzesa@sze.hu \\ Péter Csavajda \\ Széchenyi István University \\ csavajda.peter@sze.hu
}

\begin{abstract}
To control the climate when temperature sensitive drugs are delivered is an essential consideration of shippers and freight forwarders. It is common practice to utilize insulated boxes. A survey was conducted to determine the properties of these daily deliveries and factors were observed that influence the climate environment of drugs during travel. These factors included opening intervals, number of openings, trip times and distances. Then the results of the survey were used to perform the recorded circumstances of distribution in laboratory tests as close to reality as possible and analyse the effect of the abovementioned factors. During real distribution the temperature range from $2^{\circ} \mathrm{C}-8{ }^{\circ} \mathrm{C}$ was targeted. For the comparison of profiles, the static temperature profiles were also measured in the laboratory. One objective of this paper was to do a comparative performance analysis for the velocity changes of temperature between opened and not-opened procedures. A second objective was to show how to effect the vibration of temperature affects different parts of the box. The final objective was to provide packaging engineers with new information to design cost-efficient and practical reusable transportation solutions for these drugs on daily deliveries with more stopovers and openings.
\end{abstract}

Key Words: packaging, insulated box, vibration 


\subsection{INTRODUCTION}

The climate conditions in the pharmaceutical drugs supply chain are an essential consideration to protect the quality and integrity of these type of shipments. The quality of shipments concerning temperature-sensitive drugs can be seriously affected by unsatisfactory temperature fluctuations during storage and transportation from distributors to pharmacies. The required temperature ranges are usually regulated by varied insulated packaging systems. These systems protect the products from environmental temperature by different insulating materials and provide different masses and numbers of refrigerants and inner packaging inside the insulated packaging. While the box, the product and coolant properties are constant, the final ability of the package and appropriate drug temperature can be different due to the variation in distribution environmental conditions. Despite the best intentions of packaging manufacturers and logistics providers, the undetected failure to maintain drug or vaccine temperatures in an appropriate range can be catastrophic for the end user, and incurs economic losses for manufacturers and/or distributors [1].

Detecting the possible failure and damages, standard temperature conditions and testing frameworks have been created [2] to test whether the thermal insulated boxes are able to maintain the appropriate product temperatures under "extreme" conditions and during transportation. The known methods to meet the requirements for insulated boxes include physically testing and modelling the heat transfer of these boxes [3] - [7]. However, boxes that meet the required product temperature range are classified as "qualified" boxes, as opposed to "validated" boxes. The reason is that the box's performance under test conditions does not guarantee its ability to ensure the product temperature under actual environmental conditions during transport [8].
The transport of low volume temperaturesensitive drugs is commonly conducted with the use of insulated boxes and non-refrigerated delivery networks. However, during the daily distribution, the supply is provided with refrigerated trailers or vans depending on the actual outside atmospheric temperature conditions.

These chains use reusable shipping containers for the daily delivery distribution, and they also use a single (or disposable) insulated packaging-system for long-distance or single delivery services. There are difficulties in defining the optimal geometrical sizes and other parameters of reusable insulated boxes for the recurrent daily delivery distribution. The reason is that the claims from the pharmacies (consumers) are stochastic, and the quantity and quality of required drugs occurs randomly as well as the parameters of a daily delivery such as stopovers, distances and trip times. Hereby the distributors seek optimal sizes, volume capacity and structures that satisfy the extreme claims. There are a lot of disadvantages such as not-adequate temperature profiles, unknown trip times in the required temperature range, difficulty of planning the quantity of refrigerants, etc.

The ability of the packaging-system to ensure the required temperature limits during a shipment depends on factors such as the duration of transport, the size and the mass of the shipment and products, the outside temperatures and the numbers or mass of the refrigerants. Previous studies mainly focused on the evaluating "static" values such as the R-values (resistance to heat flow) of package systems and the melting points and heat absorption rates of refrigerants [4], [6], or evaluating the ability under a "dynamic" distribution environment subjected to the wall thickness of single-use packaging [3], while measuring and analysing the static characteristics of thermally insulated packaging solutions and evaluating the effect of outside or seasonal temperatures of distribution [9]. 
This paper studied the effect of openings and vibration on the temperature profiles on daily pharmaceutical drug deliveries with varied positions in the boxes and compared the results to static tests. At first, a survey was conducted to determine the properties of daily deliveries such as opening intervals, first opening, number of openings, trip times and distances, and then the results of the survey were used to perform the distribution circumstances close to the reality and analyze the effect of the mentioned factors. On real deliveries the temperature range of $2^{\circ} \mathrm{C}-8^{\circ} \mathrm{C}$ was targeted. In the comparison of profiles, the static temperature profiles were also measured in laboratory. One objective of this paper was to conduct a comparative performance analysis for the velocity changes of temperature between opened and closed procedures. A second objective was to show how to affect the vibration of temperature profiles on different parts of the box. The final objective was to provide packaging engineers with new information regarding how to design cost-efficient and practical reusable transportation solutions for these drugs by using daily deliveries, more stopovers and openings.

\subsection{SURVEY OF A REAL DISTRIBUTION}

Before the laboratory tests, two complete weekly distribution task series of a pharmaceutical distributor were surveyed in order to know the real openings and vibration circumstances of the drugs distribution. On a daily basis, the company regularly transports a wide range of differential drugs to different pharmacies in Hungary. The daily shipment contains pharmaceutical drugs and vaccines, which are varied in regards to temperature sensitivity. The sensitive drugs travel together with the nonsensitive drugs in the same van but a refrigerated compartment is used depending on the season and the outside temperature in order to keep the temperature below $23^{\circ} \mathrm{C}$. Figure 1 shows the observed delivery vehicle. The instruction for the driver is to hold the air temperature between $15^{\circ} \mathrm{C}$ and $23^{\circ} \mathrm{C}$ in the van. If the temperature is over $23^{\circ} \mathrm{C}$, then the climate control system must be switched on. For ease and efficiency, the daily shipments are sent out from Budapest, Hungary, which is centrally located. These daily deliveries were examined.

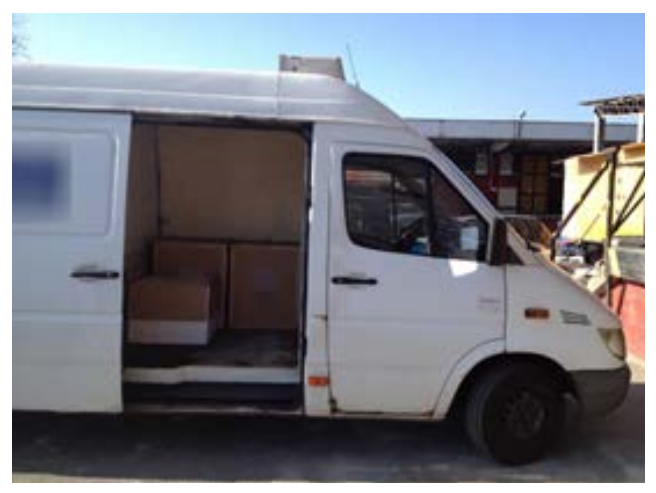

Figure 1: The delivery van

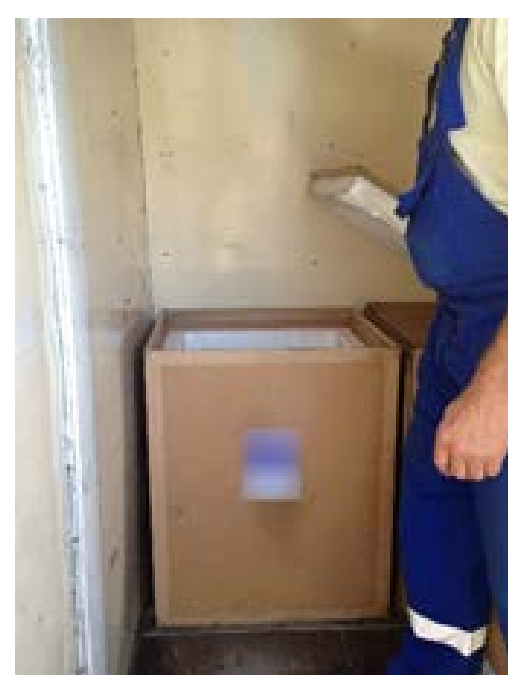

Figure 2: The Insulated Box 
For the delivery of the sensitive drugs, reusableor returnable insulated boxes were always used. The examined drugs required a temperature between 2$8^{\circ} \mathrm{C}$. The insulated box observed in this study and used later at the laboratory test is shown in Figure 2. The refrigerants used were 10 gel packs. The sensitive drugs were stored at approximately $5{ }^{\circ} \mathrm{C}$ before delivery. The mass of these sensitive drugs varied but could be calculated between 1 and 3 kilograms based on their pack labels.

\subsection{DETAIL OF THE INSULATED BOX AND PACKAGINGACCESSORIES}

The inner geometrical size of the box was $575 \times 395 \times 452 \mathrm{~mm}$ with total surface area $1,336 \mathrm{~m}^{2}$, weighed 5,65 kilograms. It was built up from a five-layer corrugated fibreboard box (BC flute, fibreboard manufactured by Dunapack Hungary Ltd., box produced by Volanpack Ltd., Hungary) provided with a removable lid. Each side was coated with $50 \mathrm{~mm}$ thick expanded polystyrene (EPS, manufactured by Hungipack Ltd. Hungary) foam insulation. The EPS foam (density $18 \mathrm{~kg}$ / $\mathrm{m}^{3}$ ) was fastened to the sidewalls with gluing (supplied by Unitech Ltd., Hungary). Polyethylene bag $(60 \mu \mathrm{PE}$, manufactured by Csom $2001 \mathrm{Ltd}$, Hungary) and a corrugated paper master-box (23B flute, manufactured by Duropack Ltd. Hungary) were used as protective secondary internal packaging. Corrugated paperboard was applied to the bottom layers in order to prevent direct contact between the refrigerants and samples.

The R-value (for 24h) for insulated box was also measured as presented in the paper of Singh et al. in 2008 [5]. The average system R-value of the box was $1,92 \mathrm{~m}^{2}{ }^{\circ} \mathrm{C} / \mathrm{W}$.

\subsection{THE GEL PACKS}

The reusable refrigerants used were produced by EZETIL (GEL blue Ice Long Time Performance Accus, IPV GmbH, Germany) and packed in PE containers. They weighed about $440 \mathrm{~g} \pm 2 \%$, measuring 204 x 105 x $40 \mathrm{~mm}$. These were filled up with liquid by the manufacturer and were cooled down to $-18^{\circ} \mathrm{C}$ in accordance with producers' lower limit recommendation before delivery for 48 hours.

At this point, our survey focused on the specifics of the deliveries such as the number of travel stops and distances, the entire traveling time, the time interval between box openings and the opening intervals. These data were repeatedly recorded for the test interval of two weeks. The recording of the data lasted until the last drug was removed from the insulated box. Tables 1 and 2 show the data for the deliveries. Figure 3 shows a sample delivery from the survey. (See next page) 
Table 1: Survey of the $1^{\text {st }}$ week distribution

\begin{tabular}{|c|c|c|c|c|c|c|c|c|c|c|c|c|c|c|c|}
\hline \multirow[b]{2}{*}{ ș } & \multicolumn{3}{|c|}{ Monday } & \multicolumn{3}{|c|}{ Tuesday } & \multicolumn{3}{|c|}{ Wednesday } & \multicolumn{3}{|c|}{ Thursday } & \multicolumn{3}{|c|}{ Friday } \\
\hline & 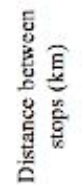 & 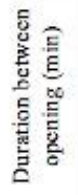 & 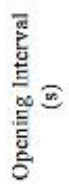 & 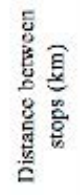 & 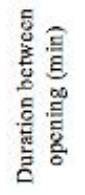 & 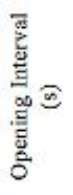 & 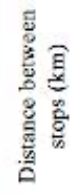 & 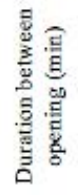 & 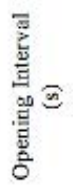 & 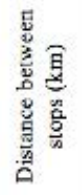 & 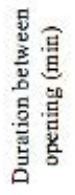 & 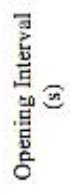 & 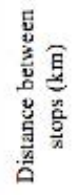 & 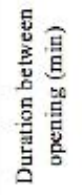 & 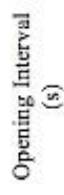 \\
\hline 0 & Depot & $\cdot$ & - & Depot & - & - & Depot & - & - & Depot & - & - & Depot & - & - \\
\hline 1 & 229 & 246 & $0: 17$ & 123 & 92 & $0: 21$ & 118 & 96 & $0: 22$ & 174 & 125 & $0: 26$ & 138 & 95 & $0: 23$ \\
\hline 2 & 64 & 137 & $0: 25$ & 143 & 135 & $0: 34$ & 1 & 6 & $0: 17$ & 2 & 9 & $0: 21$ & 98 & 72 & $0: 24$ \\
\hline 3 & Depot & - & - & ss & 65 & $0: 28$ & 2 & 29 & $0: 15$ & 6 & 14 & $0: 17$ & 22 & 27 & $0: 20$ \\
\hline 3 & & & & 4 & 19 & $0: 30$ & 7 & 18 & $0: 30$ & 31 & 33 & $0: 23$ & 57 & 69 & $0: 24$ \\
\hline 4 & & & & 64 & 123 & $0: 16$ & 15 & 27 & $0: 20$ & 28 & 28 & $0: 18$ & Depot & - & - \\
\hline 5 & & & & Depot & - & - & 41 & 48 & $0: 18$ & Depot & - & - & & & \\
\hline 6 & & & & - & & & 89 & 114 & $0: 20$ & & & & & & \\
\hline \multirow[t]{4}{*}{7} & & & & & & & Depot & - & - & & & & & & \\
\hline & Loaded & istanee: & 293 & \multirow{2}{*}{\multicolumn{2}{|c|}{$\begin{array}{l}\text { Loaded distanec: } \\
\text { Last opening } \\
\text { minutes: }\end{array}$}} & 389 & \multirow{2}{*}{\multicolumn{2}{|c|}{$\begin{array}{l}\text { Loaded distance: } \\
\text { Last opening } \\
\text { minutes: }\end{array}$}} & 273 & Loaded & istance: & 241 & \multirow{2}{*}{\multicolumn{2}{|c|}{$\begin{array}{l}\text { Loaded distanee: } \\
\text { Last opening } \\
\text { minutes: }\end{array}$}} & 315 \\
\hline & $\begin{array}{l}\text { Last } \\
\text { mir }\end{array}$ & $\begin{array}{l}\text { ening } \\
\text { es: }\end{array}$ & 383 & & & 434 & & & 338 & $\begin{array}{r}\text { Last } \\
\text { min }\end{array}$ & $\begin{array}{l}\text { ening } \\
\text { tes: }\end{array}$ & 209 & & & 263 \\
\hline & $\begin{array}{l}\text { Avg. } \\
\text { pe }\end{array}$ & $\begin{array}{l}\text { ening } \\
\text { d: }\end{array}$ & $0: 21$ & \multicolumn{2}{|c|}{$\begin{array}{l}\text { Avg, opening } \\
\text { period: }\end{array}$} & $0: 26$ & \multicolumn{2}{|c|}{$\begin{array}{l}\text { Avg. opening } \\
\text { period: }\end{array}$} & $0: 20$ & $\begin{array}{l}\text { Avg. } \\
\text { pe }\end{array}$ & ening & $0: 21$ & \multicolumn{2}{|c|}{$\begin{array}{l}\text { Avg. opening } \\
\text { period: }\end{array}$} & $0: 22$ \\
\hline
\end{tabular}

Table 2: Survey of the $2^{\text {nd }}$ week distribution

\begin{tabular}{|c|c|c|c|c|c|c|c|c|c|c|c|c|c|c|c|}
\hline \multirow[b]{2}{*}{$\frac{a}{D^{2}}$} & \multicolumn{3}{|c|}{ Monday } & \multicolumn{3}{|c|}{ Tuesday } & \multicolumn{3}{|c|}{ Wednesday } & \multicolumn{3}{|c|}{ Thursday } & \multicolumn{3}{|c|}{ Friday } \\
\hline & 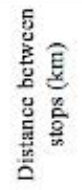 & 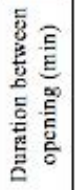 & 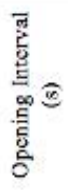 & 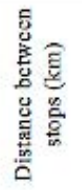 & 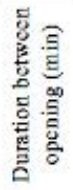 & 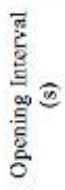 & 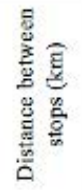 & 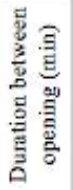 & 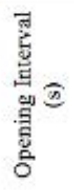 & 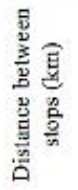 & 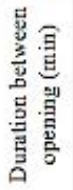 & $\begin{array}{l}\text { 荡 } \\
\text { 点 } \\
\text { 点 } \\
0\end{array}$ & 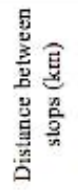 & 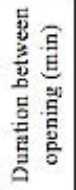 & 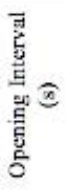 \\
\hline 0 & Depot & - & - & Depot & - & - & Depot & - & - & Depot & - & - & Depot & - & - \\
\hline 1 & 65 & 55 & $0: 18$ & 21 & 29 & $0: 25$ & 65 & 49 & $0: 22$ & 212 & 136 & $0: 25$ & 90 & 76 & $0: 27$ \\
\hline 2 & 11 & 24 & $0: 20$ & 27 & 25 & $0: 32$ & 49 & 58 & $0: 17$ & 76 & 82 & $0: 31$ & 23 & 35 & $0: 23$ \\
\hline 3 & 20 & 29 & $0: 18$ & 49 & 59 & $0: 24$ & 51 & 57 & $0: 15$ & 31 & 34 & $0: 21$ & 52 & 61 & $0: 18$ \\
\hline 3 & 48 & 69 & $0: 16$ & 51 & 65 & $0: 23$ & 27 & 32 & $0: 30$ & 64 & 77 & $0: 25$ & 32 & 47 & $0: 21$ \\
\hline 4 & Depot & - & - & Depot & - & - & 86 & 74 & $0: 20$ & 28 & 26 & $0: 18$ & 50 & 54 & $0: 16$ \\
\hline \multirow[t]{4}{*}{5} & & & & & & & Depot & - & - & Depot & - & - & Depot & - & - \\
\hline & \multicolumn{2}{|c|}{$\begin{array}{l}\text { Loaded } \\
\text { distance: }\end{array}$} & 144 & $\begin{array}{l}\text { Loa } \\
\text { dista }\end{array}$ & & 148 & \multicolumn{2}{|c|}{$\begin{array}{l}\text { Loaded } \\
\text { distance: }\end{array}$} & 278 & \multicolumn{2}{|c|}{$\begin{array}{l}\text { Loaded } \\
\text { distanec: }\end{array}$} & 411 & \multicolumn{2}{|c|}{$\begin{array}{l}\text { Loaded } \\
\text { distanec: }\end{array}$} & 247 \\
\hline & \multicolumn{2}{|c|}{$\begin{array}{l}\text { Last opening } \\
\text { minutes: }\end{array}$} & 177 & $\begin{array}{l}\text { L.ast op } \\
\text { minu }\end{array}$ & $\begin{array}{l}\text { ning } \\
\text { s: }\end{array}$ & 178 & \multicolumn{2}{|c|}{$\begin{array}{l}\text { Last opening } \\
\text { minutes: }\end{array}$} & 270 & \multicolumn{2}{|c|}{$\begin{array}{l}\text { Last opening } \\
\text { minutes: }\end{array}$} & 355 & \multicolumn{2}{|c|}{$\begin{array}{l}\text { Last opening } \\
\text { minutes: }\end{array}$} & 273 \\
\hline & \multicolumn{2}{|c|}{$\begin{array}{l}\text { Avg. opening } \\
\text { period: }\end{array}$} & $0: 18$ & $\begin{array}{l}\text { Avg. of } \\
\text { peri }\end{array}$ & ang & $0: 26$ & \multicolumn{2}{|c|}{$\begin{array}{l}\text { Avg. opening } \\
\text { period: }\end{array}$} & $0: 20$ & \multicolumn{2}{|c|}{$\begin{array}{l}\text { Avg. opening } \\
\text { period: }\end{array}$} & $0: 24$ & \multicolumn{2}{|c|}{$\begin{array}{l}\text { Avg. opening } \\
\text { period: }\end{array}$} & $0: 21$ \\
\hline
\end{tabular}




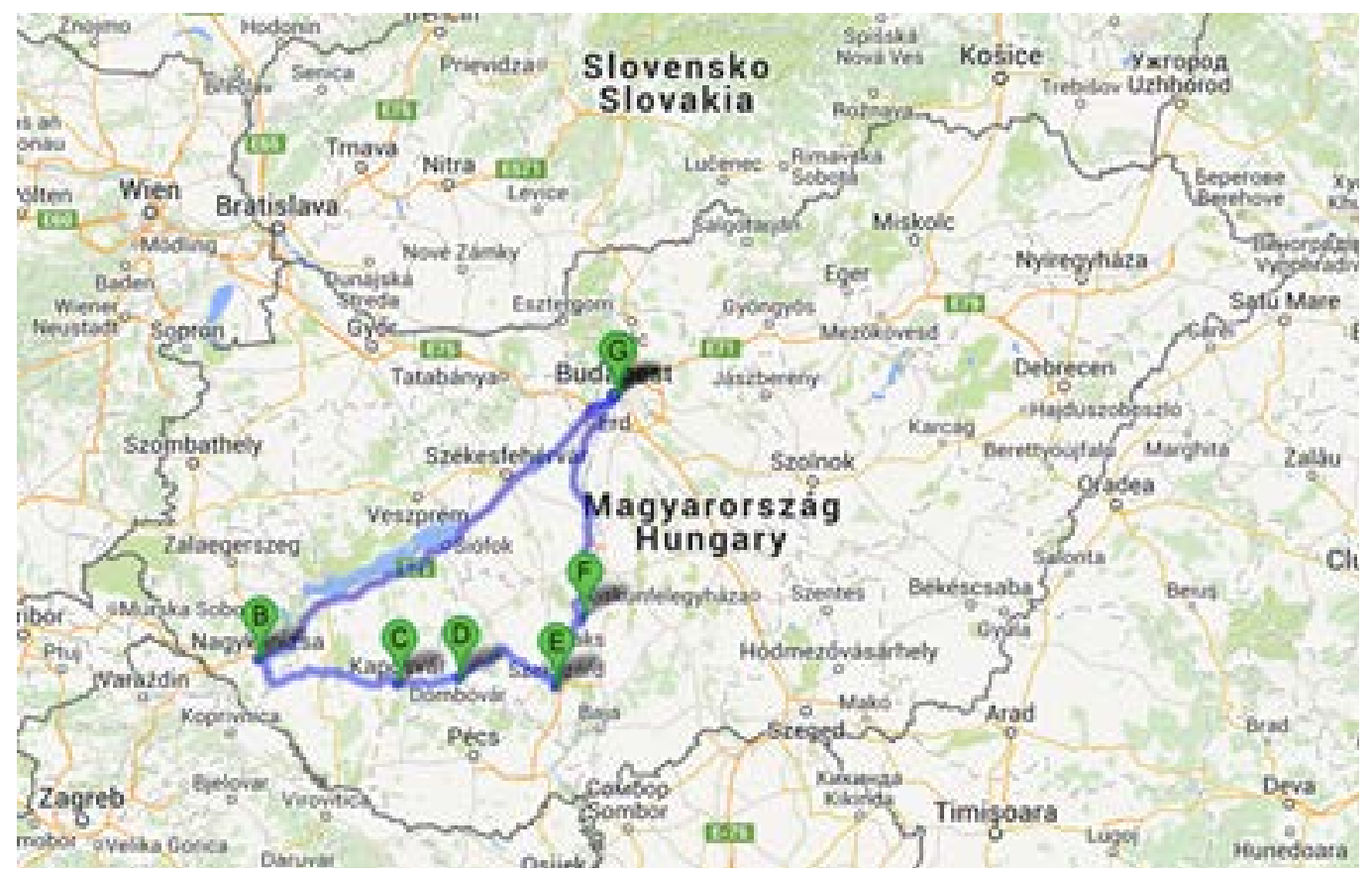

Figure 3. An example tour of the daily deliveries

The data in Table 3 the opening intervals. This is because the unpack and pack the internal packaging and to assort the right drugs to the given pharmacy.

Table 3. Summarized results of the surveys'details

\begin{tabular}{lccc}
\hline & Min. & Avg. & Max. \\
\hline Number of openings (times) & 2 & 4,6 & 7 \\
First opening (min) & 29 & 99 & 246 \\
Latest opening (min) & 177 & 288 & 434 \\
Duration between openings (min) & 6 & 62 & 137 \\
Distance till the box had been empty (km) & 144 & 274 & 411 \\
Opening intervals (s) & 15 & 22 & 34 \\
\hline
\end{tabular}

It also must be noted that the delivery services record the temperature in the insulated box, in the event that a particular pharmacy requests this information. Measuring the temperatures can become complicated, seeing that there is no exact location for the measuring sensor. In addition to this, there are normally temperature fluctuations whenever the door of the van is opened, which allows outside air to influence the temperature on the inside of the van. 


\subsection{MEASUREMENT IN THE LABORATORY AND THE TEST METHOD}

\subsection{MEASUREMENT EQUIPMENT}

The laboratory measurements were conducted in order to observe the temperature changes inside the box alongside the vibration and openings. In the laboratory tests the same insulated box with the same accessories (10 gel packs, a PE bag, a corrugated fibreboard (CFB) master-box, 1 seperating cardboard sheet) were applied as they were in the real survey. The assembly is shown in Figure 4. The substitute products were six half bottles were conditioned at $+5^{\circ} \mathrm{C}$ for $48 \mathrm{~h}$ prior to the test, as the gel packs were at $-18^{\circ} \mathrm{C}$ for 48h.Two CLIMATS 2223-HA climate chambers were used in order to freeze the gel packs and bottles of water.

A TIRA TV59355/AIT-640 vibration test system and an ANGELANTONI ACS ANYVIB climate chamber were used for the vibration and controlled climate conditioning. The accuracy of the climate chamber is $\pm 0.1^{\circ} \mathrm{C}$ between $0^{\circ} \mathrm{C}$ and $40^{\circ} \mathrm{C}$. Figure 5 shows the vibration system with the climate chamber.
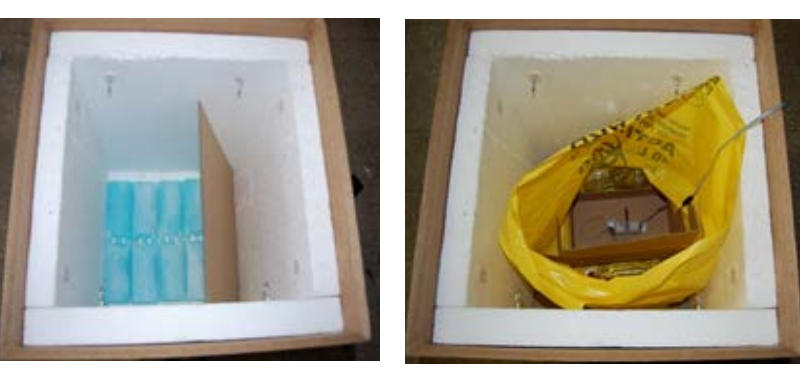

Figure 4: The assembly of insulted box measured
Laboratory-made temperature data loggers with 11 active channels inside were used to monitor the temperature in the insulated box. The temperature sensors were calibrated with an accuracy of $\pm 0.1^{\circ} \mathrm{C}$ on the range of $-10^{\circ} \mathrm{C}$ to $30^{\circ} \mathrm{C}$, working with a resolution of $0.1{ }^{\circ} \mathrm{C}$. One active channel recorded the outside temperature. This system can be also seen on Figure 4 and built up from the following:

- 1 pc Microchip PIC18F25J50-I/SO (MCU, 8BIT, 32K FLASH, USB, 28SOIC)

- 2 pes IC NXP PCA9546AD (Switch, 4CH, I2C, 16SOIC)

- 2 pcs AMIC A25L080M-F (MEMORY, FLASH, SPI, 8M, 8SOP)

- 2 pcs IQD Frequency products

- XTAL003000- 85SMX (Crystal $32.768 \mathrm{kHz})$

- 11 pcs Microchip MCP9804-E/MS (IC, TEMP SENSOR, I2C, 2.7V, 8MSOP)

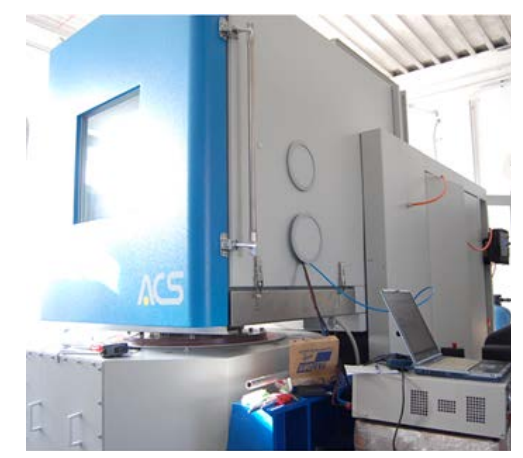

Figure 5: The vibration-climate system
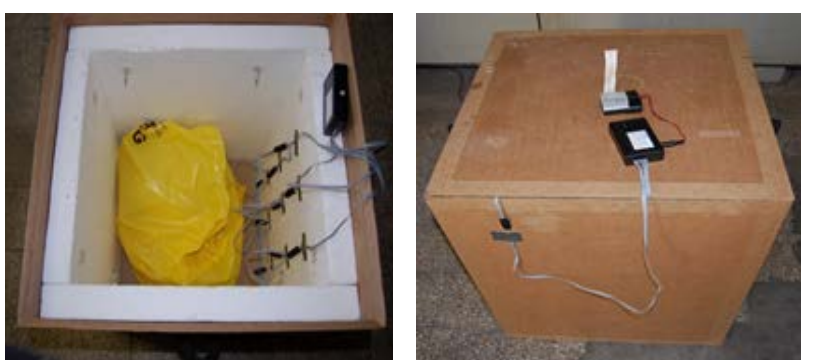


\subsection{TEST CONDITION AND METHOD}

Four different tests were performed to study the effect of openings, vibration and the impact of the two together with the temperature profiles inside the box. The bases of the test configurations were defined by the summarized results of the former shown survey with such an adequate test severity, which allows observing the possible effects of real processes. The following test conditions and variations were determined by the survey.

\section{Variations:}

- Testing with vibration and openings (vibrated, opened)

- Testing with vibration only (vibrated, notopened)

- Testing with openings only (static, opened)

- Testing without openings and vibration (static, non-opened)

\section{Conditions:}

- Test duration: 350 minutes

- The first opening time: after 100 minutes

- Duration between openings: 50 minutes

- Numbers of openings: 6 times

- Openings' interval: 30 seconds

- Temperature in climate chamber: $23 \pm 0,1^{\circ} \mathrm{C}$

- Vibration intensity and test duration: calculated by ISTA 7D

All four of the tests were performed in the climate chamber at $23^{\circ} \mathrm{C}$. As mentioned earlier, if the outside temperature is above $23^{\circ} \mathrm{C}$, the driver has to turn the climate system on, so the test tried to assure that the upper limit was achieved throughout the tests as it is the outside temperature that has the most significant effect on the inside temperature. Similar to the above, the intervals and number of openings were also defined to ensure an approximate maximum stress. Because the first opening time and the duration between openings are very random, the average values were applied to the test setups. In each test, when an opening occurred, one bottle was taken from the box to simulate the effect of weight loss of the taken drugs. The ISTA 7D vibration profile was used during the test, but the Grms intensity was modified from $1,15 \mathrm{Grms}$ to $0,34 \mathrm{Grms}$ and test time from 30 to 350 minutes by the test time accelerated formula of Kipp [10]. The vibration was performed only in the shipping orientation.

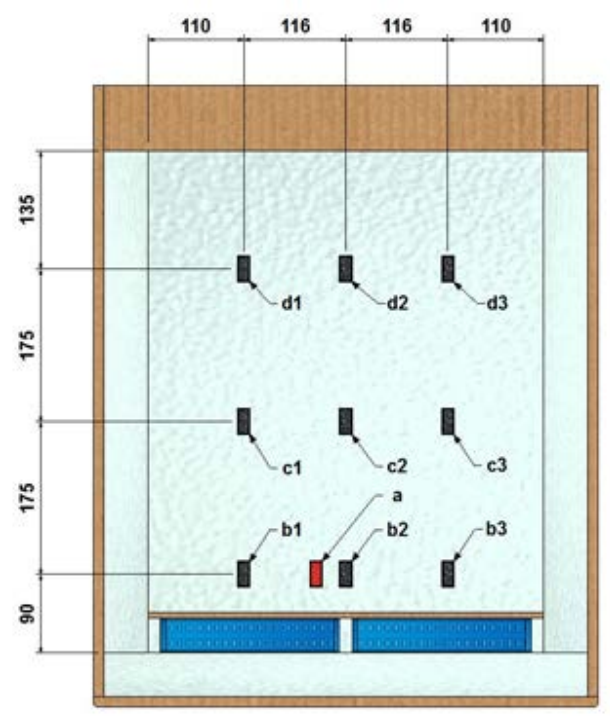

Figure 6. Layout of the temperature sensors

Figure 6 shows the layout of the temperature sensors. One sensor was in the inner packaging (fully inside sensor) and nine were close to the sidewall. The sensors were setup to record the temperature every minute. The heights of the sensors on the wall were adjusted to the inner box sizes The bottom three sensors and the inside sensor were placed at the same height. The sensors, which were in the box but not in the inner packaging, were fastened to the wall in such a way that they did not touch the wall or the inner packaging directly. The sensors 
were provided with the following marks: the fully inside sensor was called ' $a$ ', the sensors in the first row from the bottom were called ' $b 1, \mathrm{~b} 2, \mathrm{~b} 3$ ', in the second row 'c1, c2, c3' and in the third one ' $\mathrm{d} 1, \mathrm{~d} 2$, d3'. In this way, at the evaluation and analysis an average value was calculated for each row with a temperature value in the place of ' $b$ ', 'c' and ' $d$ '.

\subsection{DATA AND RESULTS}

The first set of the analysed results deal with the measured values at the location of sensor "a" shown in Figure 7 below. In this case, the effects of vibration and opening events can be observed completely inside the insulated box, PE bag and in the paper box as well. It can be seen on the first capture that a significant difference can be observed between opened and not-opened tests. In each of the four tests the temperature went under the upper limit within 12 minutes and there were no under-cooled periods where the temperature was below the bottom limit.

Figure 7: Temperature profiles measured in the location ' $a$ '
The small temperature differentials around the minimum points were created by the short delay between getting the boxes closed, closing the climate chamber and starting the expected program. These are the reasons why during the vibrated versus static versions a minimal temperature differential could be observed. The minimum temperature recorded periods were between 70 and 95 minutes. During the opened tests in both the static and vibrated environment, the temperature went out of the limits after about 305 minutes, while during the notopened environment the temperature stayed within the limits until the end of the test. The maximum temperature deviation between the vibrated and static environment was $0.5^{\circ} \mathrm{C}$ during the not opened test (in 31st min), and was $1.4^{\circ} \mathrm{C}$ during the opened test (in 25th min.). Eventually, the vibration did not have any significant effect on location 'a', except at the end of opened tests when a small compensate role could be found and where the curves became closer. Between the last recorded minimum value and last recorded data the highest and lowest average velocity of temperature change was $1.51^{\circ} \mathrm{C} / \mathrm{h}$ during opened tests, as it was $0.76^{\circ} \mathrm{C} / \mathrm{h}$ during the notopened test.

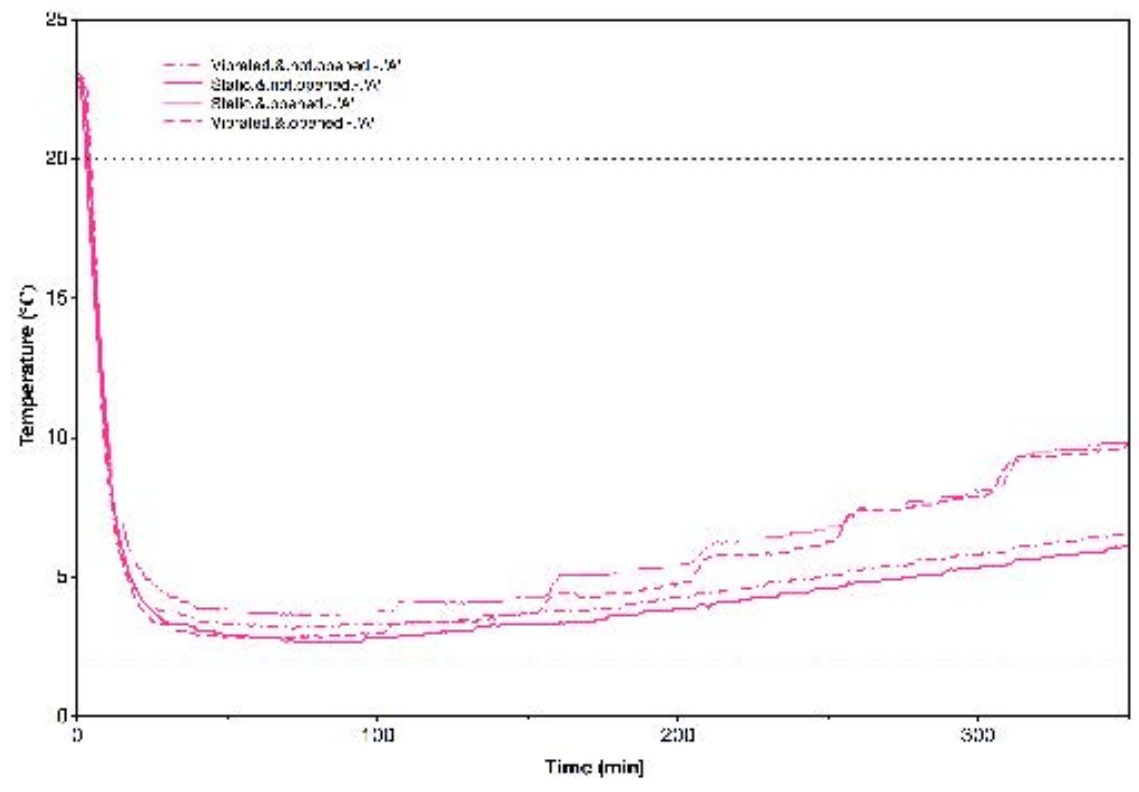




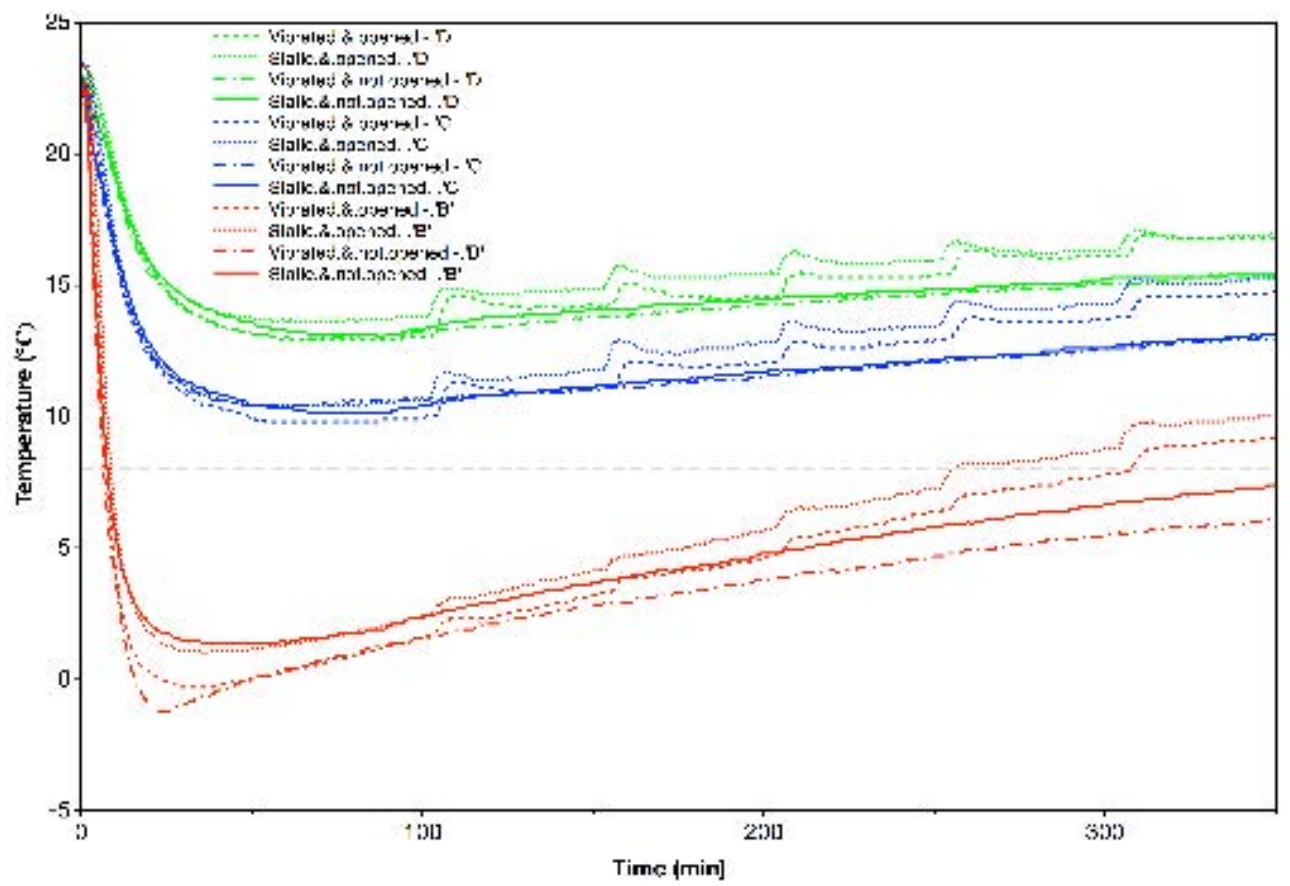

Figure 8: Temperature profiles in the locations of ' $b$ ' ' $c$ ' and ' $d$ '

In the second step, the temperature values of sensors ' $b$ ', 'c' and 'd' were compared. Figure 8 shows the results below. As it was previously expected in the case of both static and vibrated environments where the sensor was close to the gel packs and was not in the PE bag (and in their box), an overcooling period was measured very soon after starting the test and later the temperature increased faster. In the case of the vibration environment, the dwelling time under the lower limit was about 100 minutes, while it was 70 minutes during the static. The measured minimums in the ' $b$ ' position were $-1.1^{\circ} \mathrm{C}$ in the vibrated environment and $+1.2^{\circ} \mathrm{C}$ in the static. During the open test when there was no vibration, the values left the 2-8 degrees limit 49 minutes quicker. It can be concluded that the vibration has an equalizing effect in location ' $b$ '.

In the locations of ' $c$ ' and ' $d$ ', the recorded values were outside the limits throughout the whole measurement but the effects of the openings were also well observed. As a difference was predicted in the rates to the height of the sensor positioned at the top, we measured a significant difference in the most bottom sensor. It is also noticeable that when the sensor is placed higher, the average temperature change decreases. Naturally, the opened tests were also unfavourable compared to the static ones, and they can be observed with a slightly faster change in temperature. When the vibration was applied, the temperature in location ' $b$ ' also exceeded the upper limit similar to temperature in location ' $a$ '. During the static test the temperature in location ' $b$ ' exceeded the upper limit 48 min earlier.

Table 4 contains the average velocity of temperature changes for each of the locations and curves. Between the minimum and last recorded data, the highest and lowest average velocity of temperature changes were $1.83^{\circ} \mathrm{C} / \mathrm{h}$ in location ' $\mathrm{b}$ ' and $0.51{ }^{\circ} \mathrm{C} / \mathrm{h}$ in location ' $\mathrm{d}$ '. 
Table 4 . The velocity of temperature changes

\begin{tabular}{lcccc}
\hline & $\begin{array}{c}\text { Vibration } \\
\text { opened }\end{array}$ & $\begin{array}{c}\text { Vibration not- } \\
\text { opened }\end{array}$ & Static opened & $\begin{array}{c}\text { Static not- } \\
\text { opened }\end{array}$ \\
\cline { 2 - 5 } & \multicolumn{4}{c}{ Velocity of temperature chenge $\left({ }^{\circ} \mathrm{C} / \mathrm{h}\right)$} \\
\hline Location ' $\mathrm{a}$ ' & 1,41 & 0,76 & 1,51 & 0,80 \\
Location ' $^{\mathrm{b}}$ ' & 1,83 & 1,35 & 1,74 & 1,25 \\
Location ' $^{\mathrm{c}}$ ' & 1,18 & 0,57 & 1,11 & 0,69 \\
Location ' $\mathrm{d}$ ' & 0,91 & 0,51 & 0,76 & 0,55 \\
\hline
\end{tabular}

Table 4
In the final step, the effect of vibration was analysed. Figure 9 summarizes the differentials at the opened versus not-opened curves as well as the vibrated and static environments for each location. Significant differences $\left(>1^{\circ} \mathrm{C}\right)$ could be found in the location of sensor ' $b$ ' both in the opened and notopened and mainly kept between 10 and 60 minute. This phenomena can be observed after 200 minutes. At the higher locations there were no significant differences. After the first opening ( $>100 \mathrm{~min})$ the differences decreased, even in the location of sensor ' $b$ '.

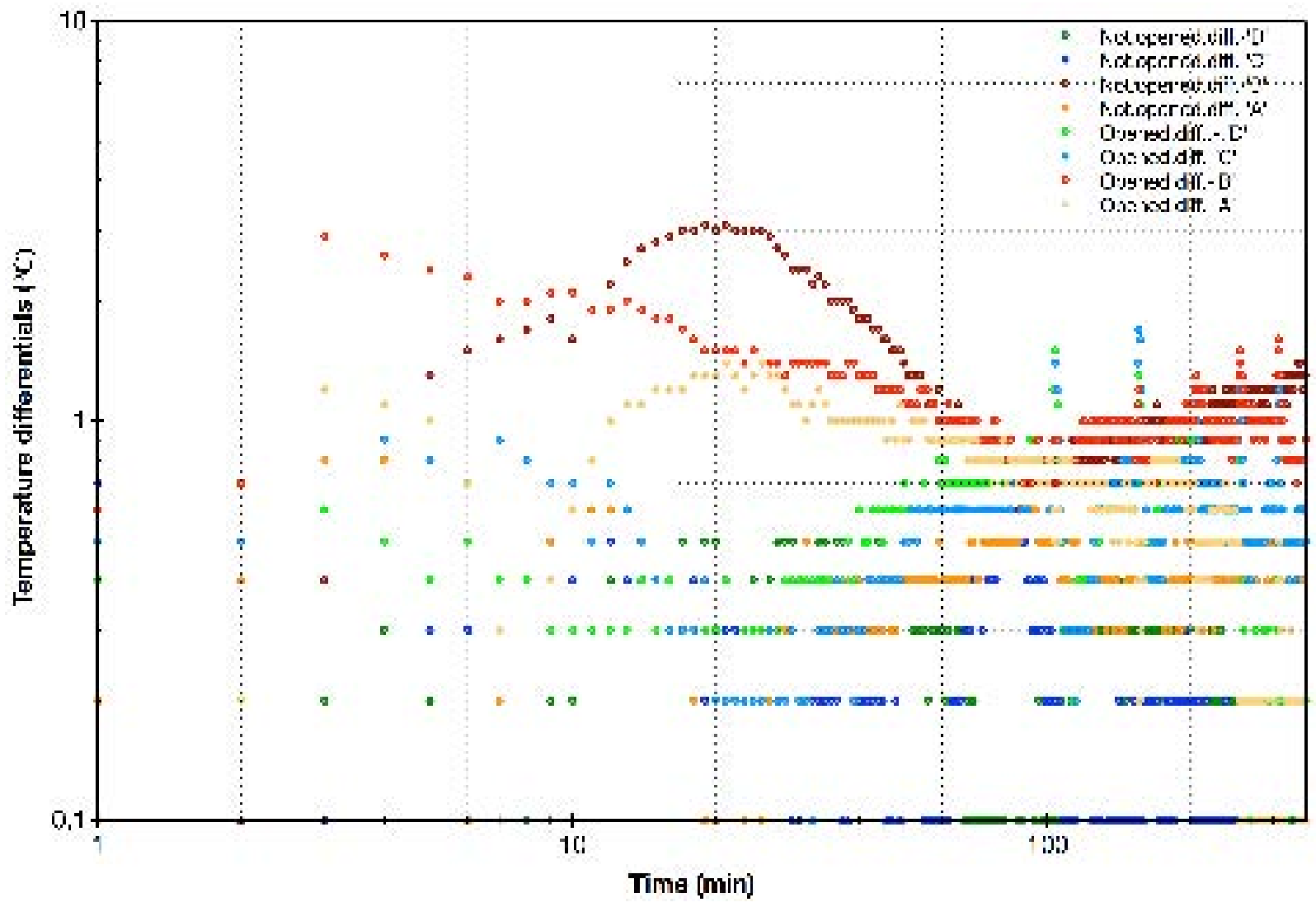

Figure 9: Differentials of temperature values between vibrarted and static tests 


\subsection{CONCLUSION}

Based on the experience of the survey and results of the measurement, the following conclusions can be drawn:

- The opening of insulated boxes during deliveries with more stopovers can have a critical effect on temperature regulation. Even though the inner packaging was used, the temperature values exceed the upper limit after 305 minutes.

- The temperature values specific to the higher levels did not go into the expected limits but the effect of the openings could also be observed. The results showed that the change of temperature change on these levels was lower than it was close to bottom sections.

- In the inner packaging beside the openings, the velocity of temperature change was almost twice as much as it was during the not-opened tests.
- The effect of vibration has a $10-15 \%$ temperature decreasing effect in the initial phases but it disappears once the boxes are opened. On the lower levels where there was no inner packaging, the vibration had an under-cooling effect and later transitioned into a favourable equalizing effect.

- The results help to ensure that how a desired product temperature can be maintained in boxes with optimal geometrical dimensions, inner packaging and adequate quantity of refrigerants through the entire distribution process, thereby decreasing the related packaging and logistics costs.

- The data and results from this study can be used to compare insulated box test methods used by packaging engineers and to develop test methods in daily delivery drug distribution. 


\section{REFERENCES}

[1] East, A., N. Smale, and S. Kang "A method for quantitative risk assessment of temperature control in insulated boxes," International Journal of Refrigeration 32.6, pp. 1505-1513, 2009.

[2] ISTA, 2014b. 7E. Testing Standard for Thermal Transport Packaging Used in Parcel Delivery System Shipment ISTA 7 Series Development Test Procedure. International Safe Transit Association

[3] Singh, Jay, Sanjiv Jaggia, and Koushik Saha, "The Effect of Distribution on Product Temperature Profile in Thermally Insulated Containers for Express Shipments," Packaging Technology and Science 26.6, pp. 327-338, 2013.

[4] Burgess, Gary, "Practical thermal resistance and ice requirement calculations for insulating packages," Packaging Technology and Science 12.2, pp. 75-80, 1999.

[5] Singh, S. P., Gary Burgess, and Jay Singh, "Performance comparison of thermal insulated packaging boxes, bags and refrigerants for single parcel shipments," Packaging Technology and Science 21.1, pp. 25-35, 2008.

[6] Matsunaga, Kazuhisa, Gary Burgess, and Hugh Lockhart, "Two methods for calculating the amount of refrigerant required for cyclic temperature testing of insulated packages," Packaging Technology and Science, 20.2, pp. 113-123, 2007.
[7] Choi, Seung-Jin, and Gary Burgess, "Practical mathematical model to predict the performance of insulating packages," Packaging Technology and Science 20.6, pp. 369-380, 2007.

[8] Bishara, Rafik H, "Qualification versus validation and good cold chain management practices," Pharmaceutical Manufacturing and Packing Sourcer, Autumn 2005 edition, pp 102-106, 2005.

[9] James, S. J., C. James, and J. A. Evans, "Modelling of food transportation systems-a review," International Journal of Refrigeration 29.6, pp. 947-957, 2006.

[10] Kipp, William I, "Vibration Testing Equivalence, How Many Hours Of Testing Equals How Many Miles Of Transport," in Proceedings of ISTA Con 2000 